\title{
KAJIAN DAMPAK PEMBANGUNAN KAWASAN PERKANTORAN KABUPATEN MANOKWARI SELATAN TERHADAP LIMPASAN PEMUKAAN DI SUBDAS RANSIKI
}

\author{
Khristian Enggar Pamuji ${ }^{1}$, Nur Alzair ${ }^{2}$ \\ ${ }^{1}$ Jurusan Fisika FMIPA UNIPA \\ ${ }^{2}$ Jurusan Teknik Geologi FTTP \\ Jl. Gunung salju Amban, Manokwari \\ e-mail : k_enggar_p@yahoo.com
}

\begin{abstract}
Abstrak
Penelitian ini dilakukan di area Pembangunan Kawasan perkantoran pemerintahan Kabupaten Manokwari Selatan, Papua Barat. Tujuan penelitian adalah untuk memperkirakan dampak perubahan tutupan lahan akibat pembangunan kawasan perkantoran terhadap debit limpasan pemukaan pada sub DAS Ransiki.

Lokasi kajian berada di sub Daerah Aliran Sungai Ransiki Kabupaten Manokwari Selatan. Kajian ini dimulai dengan pengumpulan data serta analisis data primer dan data sekunder. Data yang dikumpulkan berupa data curah hujan Manowkari Selatan, dimensi sungai dan data spatial tutupan lahan di DAS Ransiki. Data-data tersebut kemudian digunakan untuk mengetahui debit limpasan permukaan dan kapasitas tapung maksimum badan air atau sungai.

Hasil yang diperoleh dari kajian menunjukan bahwa, SubDAS Ransiki memiliki debit limpasan permukaan sebesar 2.676 m3/jam, dan debit limpasan yang berasal dari kompleks perkantoran sebesar 139 m3/jam. Peningkatan debit limpasan permukaan akibat pembangunan kawasan perkantoran diperkirakan masih dapat ditampung oleh aliran sungai atau badan air terdekat.
\end{abstract}

Kata kunci : Limpasan Permukaan, Kapasitas Tampung Sungai, Perubahan tutupan lahan

\section{PENDAHULUAN}

Kabupaten Manokwari Selatan merupakan sebuah kabupaten baru yang terletak di Provinsi Papua Barat. Kabupaten ini resmi dimekarkan dari Kabupaten Manokwari pada tanggal 25 Oktober 2012 dan Ransiki sebagai ibukotanya. Kabupaten Manokwari Selatan memerlukan fasilitas serta sarana prasarana pemerintahan yang mampu menunjang kegiatan pelayanan terhadap masyarakat. Fasilitas tersebut diantaranya gedung perkantoran pemerintahan dan fasilitas-fasilitas penunjang. Keberadaan gedung perkantoran pemerintahan dan fasilitas-fasilitas penunjang penting untuk menunjang aktivitas masyarakat di Kabupaten Manokwari Selatan.

Kabupaten Manokwari Selatan saat ini telah memiliki gedung kantor pemerintahan yang berada di area terpisah dan tidak strategis untuk dijangkau masyarakat, yaitu di Kompleks
Warsui dan sebagian ada di sisi Barat Jalan Raya Ransiki. Gedung-gedung kantor pemerintahan yang berada di kedua lokasi tersebut dinilai kurang layak dikarenakan kondisi bangunan yang semi permanen dan kurang tersedia fasilitas penunjang kegiatan perkantoran.

Badan Perencanaan dan Pembangunan Daerah (Bappeda) Kabupaten Manokwari Selatan berencana melakukan kegiatan pembangunan kawasan perkantoran terpusat untuk mengatasi permasalahan yang ada. Rencana pemusatan kawasan perkantoran yang disebut Kawasan Perkantoran Kabupaten Manokwari Selatan berlokasi di Distrik Ransiki. Lokasi ini memiliki seluas 161 ha, dan diberi nama kawasan "Boako" sesuai nama bukit yang direncanakan menjadi tapak bangunan Kantor Bupati dan Sekda. 
Adanya pembukaan lahan yang cukup besar, tentunya akan menimbulkan dampak lingkungan, salah satunya adalah peningkatan debit limpasan permukaan. Meningkatnya debit limpasan permukaan akan mengakibatkan bertambahnya beban Daerah Aliran Sungai, yang jika tidak dikelola dengan baik dapat menyebabkan terjadinya genangan atau banjir. Peningkatan debit limpasan permukaan ini telah menjadi kekawatiran bagi sebagian masyarakat, terutama masyarakat yang tinggal dibawah komplek perkantoran. Penelitian bertujuan untuk memperkirakan dampak perubahan tutupan lahan akibat pembangunan terhadap debit limpasan pemukaan pada sub DAS Ransiki.

\section{METODE PENELITIAN}

a) Waktu dan Tempat Penelitian Penelitian ini dilakukan selama 3 (tiga) bulan, mulai bulan Juni 2021 sampai dengan Agustus 2021. Lokasi penelitian berada di kawasan "Boako" Distrik Ransiki, Kabupaten Manowkari Selatan, dan termasuk ke dalam subDAS Ransiki.

\section{b) Metode Pengumpulan data}

Untuk menenetukan debit aliran permukaan dibutuhkan data intensitas curah hujan, luas wilayah, tutupan lahan, dan data topografi. Untuk data curah hujan, diperoleh dari Badan Meteorologi Klimatologi dan Geofisika (BMKG) terdekat, yaitu Stasiun Meteorologi Ransiki Manokwari Selatan. Manokwari. Data curah hujan yang di dapat merupakan hasil pencatatan secara time series selama 14 tahun terakhir. Sedangkan untuk luas wilayah, tutupan lahan, dan topografi, diperoleh dari analisis spasial yaitu pengolahan citra DEM-SRTM yang dipadukan dengan peta RBI melalui aplikasi QGIS.

\section{c) Metode Analisis Data}

Analisis dampak pembangunan kawasan perkantoran terhadap limpasan pemukaan di subDAS ransiki, dilakukan dengan cara menghitung debit limpasan permukaan di subDAS Ransiki, menghitung peningkatan debit limpasan akibat perubahan tutupan lahan, membandingkan debit limpasan dengan daya tampung badan air atau sungai. Berikut ini merupakan metode-metode yang digunakan :

\section{- Debit Limpasan Permukaan}

Debit limpasan permukaan ditentukan berdasarkan data intensitas curah, tutupan lahan, dan data topografi. Data curah hujan yang digunakan dalam analisis, merupakan data curah hujan Kabupaten Manokwari Selatan dari tahun 2005 sampai dengan 2018. Berdasarkan data curah hujan tersebut, kemudian dilakukan perhitungan periode ulang. Periode ulang adalah waktu hipotetik dimana probabilitas kejadian debit atau hujan dengan besaran tertentu akan disamai atau dilampaui sekali dalam jangka waktu tersebut. Untuk analisis periode ulang, dalam penelitian ini menggunakan metode Log Pearson III (Singh, 1998) seperti berikut :

$$
\log X_{T}=\overline{\log X}+\left(K_{T} S \log X\right)
$$

$\log X_{T}$ : nilai logaritma hujan rencana dengan periode ulang $\mathrm{T}$

$\log X$ : nilai rata-rata dari $\log \mathrm{X}$

$K_{T} \quad$ : faktor frekuensi

$S \log X$ : Standar deviasi $\log \mathrm{X}$

Intensitas curah hujan dihitung menggunakan persamaan Mononobe (Subarkah, 1980) berikut:

dimana

$$
I=\frac{R_{24}}{24}\left(\frac{24}{t_{c}}\right)^{\frac{2}{3}}
$$

I : Intensitas curah hujan ( $\mathrm{mm} / \mathrm{jam})$

$\mathrm{t}$ : Lamanya curah hujan / durasi curah hujan (jam)

$R_{24}$ : Curah hujan rencana dalam suatu periode ulang 
Perhitungan waktu konsentrasi menggunakan persamaan Kirpich (Kirpich, 1940).

$$
t_{c}=\left(\frac{0.87 \times L^{2}}{1000 \times S}\right)^{0.385}
$$

dimana

$$
t_{c}: \text { Waktu konsentrasi (Jam) }
$$

$\mathrm{L}$ : Panjang saluran air dari titik terjauh sampai titik yang ditinjau $(\mathrm{km})$

$S$ : Kemiringan rata-rata DAS

Adapun data tutupan lahan dan topografi yang diperoleh dari analisis spasial, digunakan untuk menentukan koefisien limpasan (runoff) yang selanjutnya digunakan untuk menentukan debit limpasan permukaan. Metode rasional merupakan metode sederhana yang digunakan dalam penelitian ini untuk memperkirakan debit puncak limpasan permukaan (Subarkah, 1980).

$$
Q_{T}=0.278 x I_{t} x\left(\sum A_{i} x C_{i}\right)
$$

dimana $Q_{T}$ : debit puncak limpasan permukaan pada periode ulang $\mathrm{T}$ tahun

$I_{t}:$ Intensitas curah hujan dengan periode ulang $t$ ( $\mathrm{mm} / \mathrm{jam})$

$\mathrm{C}_{\mathrm{i}}$ : Koefisien limpasan sub daerah pengaliran ke $\mathrm{i}$

$A_{i} \quad$ : Luas sub daerah pengaliran ke i $\left(\mathrm{Km}^{2}\right)$

\section{- Kapasitas Tampung Badan Air}

Kapasitas tampung maksimum sungai dan saluran drainase dapat diketahui dari persamaan berikut:

$$
Q_{S}=\mathrm{Axv}
$$

Dimana $Q_{S}$ : Kapasitas tempung sungai $\left(\mathrm{m}^{3} / \mathrm{jam}\right)$

$\mathrm{v}:$ kecepatan aliran $(\mathrm{m} / \mathrm{s})$

A : Luas penampang saluran $\left(\mathrm{m}^{2}\right)$
Kecepatan dapat diperoleh menggunakan persamaan manning (Holland, 1998):

$$
v=\frac{R^{\frac{2}{3}} S^{\frac{1}{2}}}{n}
$$

Dimana $\quad \mathrm{n}$ : koefisien kekasaran manning

$$
\begin{aligned}
& \mathrm{R}: \text { jari-jari hidrolis }(\mathrm{m}) \\
& \mathrm{S} \text { : kemiringan saluran }(\mathrm{m} / \mathrm{m})
\end{aligned}
$$

\section{HASIL DAN PEMBAHASAN}

\section{a) Sub DAS Ransiki}

Daerah Aliran Sungai (DAS) adalah suatu wilayah daratan yang merupakan suatu kesatuan sungai dan anak-anak sungai. DAS berfungsi menampung, menyimpan dan mengalirkan air yang berasal dari curah hujan ke danau atau ke laut secara alami. Batas DAS di darat merupakan pemisah topografi dan batas di laut sampai dengan daerah perairan yang masih terpengaruh aktivitas daratan (PP 37 Tahun 2012).

Lokasi studi merupakan bagian dari DAS Ransiki yang memiliki luas $42.748 \mathrm{Ha}$. Sungai Ransiki atau sering disebut juga Kali Mati memiliki panjang $\pm 32 \mathrm{Km}$, berhulu di pegunungan Arfak dan bermuara di Teluk Cenderawasih (Samudera Pasifik). Sungai ini memiliki debit rata-rata $76 \mathrm{~m}^{3} /$ detik, dan alirannya mengalir sepanjang tahun dan mempunyai fluktuasi debit yang tinggi dengan debit banjir relatif kecil. Bentuk DAS relatif memanjang, DAS yang memanjang dengan nilai faktor bentuk rendah maka memiliki fluktuasi banjir yang rendah dan waktu yang diperlukan oleh air sungai lebih lama (Sidral dkk, 2016). Meskipun lokasi studi merupakan bagian dari DAS Ransiki, akan tetapi aliran sungainya tidak bergabung dengan Sungai Ransiki, tetapi langsung menuju pantai timur Ransiki atau ke Samudra Pasifik. 


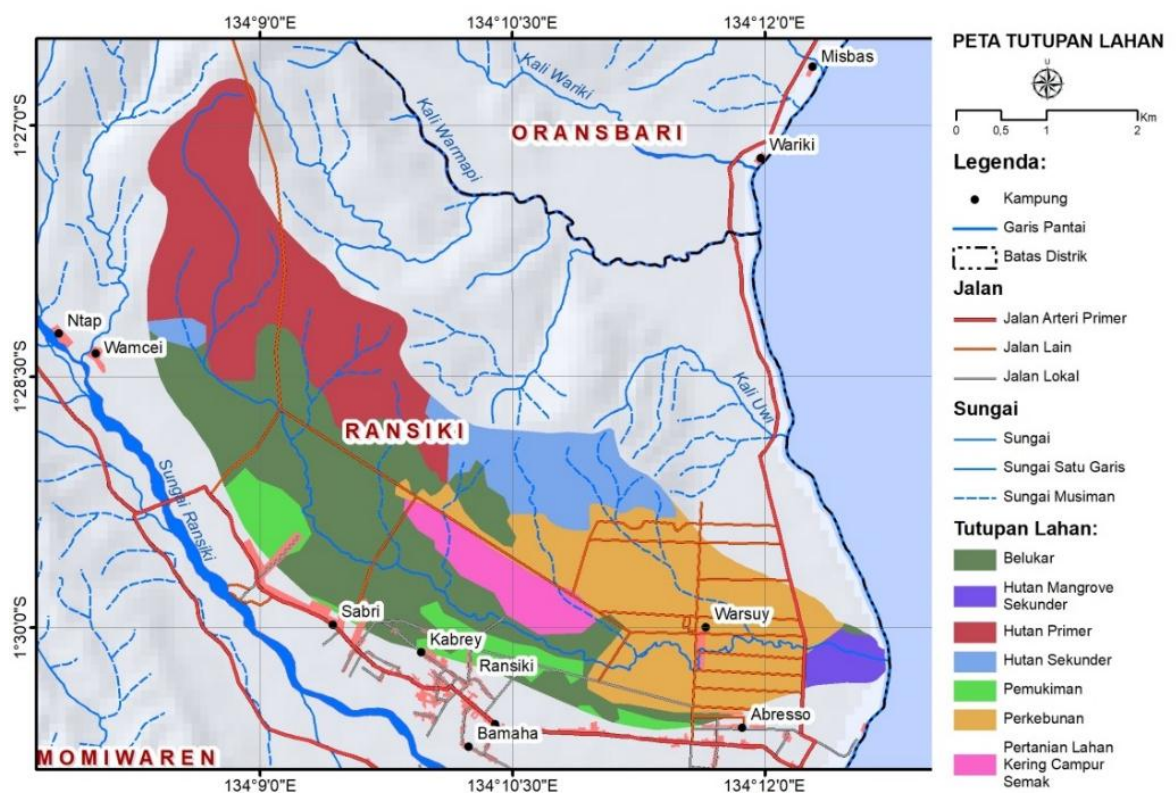

Gambar 1.Tutupan Lahan di Sub DAS Ransiki

Berdasarkan analisis spatial, subDAS Ransiki, dimana lokasi kompleks perkantoran Bupati Manokwari Selatan berada, memiliki luas 2.191,8 Ha. Dari luas tersebut, $36 \%$ arealnya masih didominasi hutan (baik hutan primer maupun sekunder), $30 \%$ berupa semak belukar, $28 \%$ digunakan untuk perkebunan dan pertanian, dan $6 \%$ sudah menjadi areal perumahan (Gambar 1). Berdasarkan peta kemiringan lahan (Gambar 2), sebagian besar atau $59.9 \%$ sub DAS, merupakan dataran rendah dengan kemiringan antara 0-8\%.

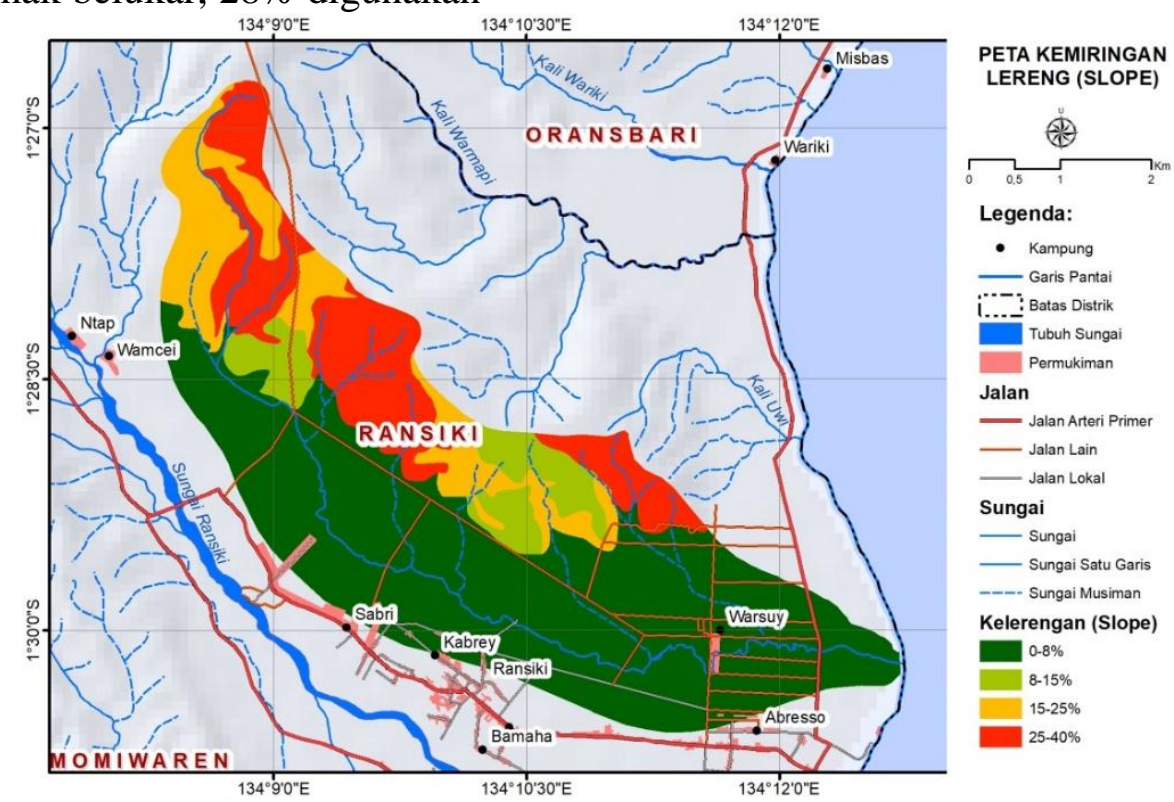

Gambar 2. Kemiringan Lahan di Sub DAS Ransiki 


\section{b) Debit Limpasan Permukaan (Run- Off) di subDAS Ransiki}

Limpasan permukaan di suatu tempat dipengaruhi oleh luas area, intensitas curah hujan, tutupan lahan, kemiringan, jenis tanah. Berikut data hasil pencatatan data Badan Meteorologi, Klimatologi, dan Geofisika (BMKG) Kabupaten Manokwari Selatan untuk tahun 2005-2018 dari Stasiun Klimatologi Manokwari Selatan. Total curah hujan tahunan rata-rata (Januari-Desember) yang jatuh di lokasi kegiatan selama 11 tahun terakhir (2009-2019) mencapai 2.710 $\mathrm{mm}$, dengan puncak curah hujan terjadi pada bulan April dan curah hujan terendah terjadi pada bulan Oktober (Gambar 3).

Berdasarkan data curah hujan tersebut, kemudian dilakukan analisis periode ulang. Periode ulang adalah waktu hipotetik dimana probabilitas kejadian debit atau hujan dengan besaran tertentu akan disamai atau dilampaui sekali dalam jangka waktu tersebut. Untuk analisis periode ulang, dalam penelitian ini menggunakan metode Log Pearson III. Sedangkan Intensitas curah hujan dihitung menggunakan persamaan Mononobe, dengan perhitungan waktu konsentrasi menggunakan persamaan Kirpich. Waktu yang diperlukan oleh titik air hujan yang jatuh terjauh pada permukaan tanah dalam sub DAS Ransiki yang memiliki luas 2.191,8 Ha ke saluran yang ditinjau diperkirakan membutuhan waktu 37 jam. Periode ulang curah hujan yang diperoleh berdasarkan metode tersebut dapat dilihat pada Tabel 1.

Selain curah hujan, limpasan permukaan juga dipengaruhi oleh tutupan lahan dan kemiringan. Berdasarkan peta tata guna lahan, lokasi stusi dapat dikelompokkan ke dalam beberapa penggunaan lahan yang luas masing-masing lahan dapat dilihat pada Tabel 2.

Dengan memperhitungkan luas tutupan lahan, koefisien run-off dan intensitas curah hujan, maka diperkirakan debit puncak aliran permukaan untuk periode ulang 2 tahun mencapai 1.564 $\mathrm{m}^{3} / \mathrm{jam}$, dan periode ulang 50 tahun mencapai $2.676 \mathrm{~m}^{3} / \mathrm{jam}$. Debit limpasan untuk tiap-tiap periode ulang dapat dilihat pada Tabel 3.

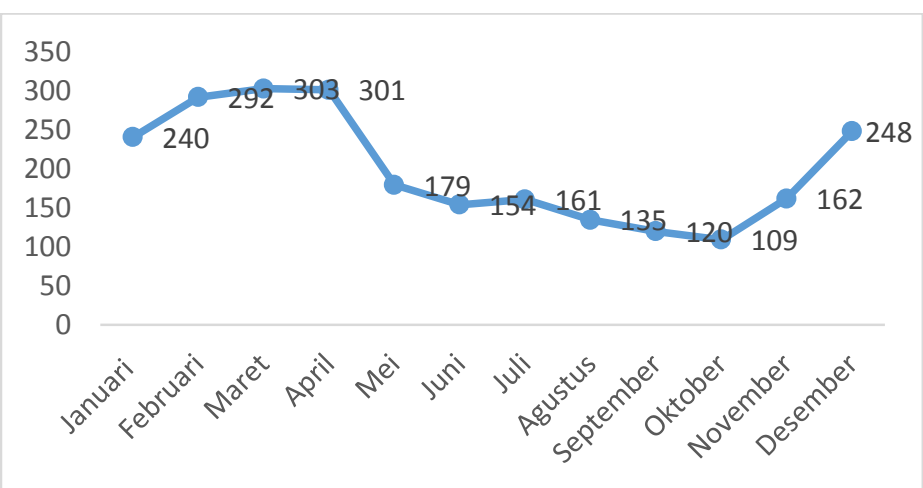

Gambar 3. Grafik Curah Hujan bulanan rata-rata Kabupaten Manokwari Selatan Tahun 2005-2018

Tabel 1. Periode Ulang Intensitas Curah Hujan

\begin{tabular}{lccccc}
\hline Periode Ulang (Tahun) & $\mathbf{2}$ & $\mathbf{5}$ & $\mathbf{1 0}$ & $\mathbf{2 5}$ & $\mathbf{5 0}$ \\
\hline Intensitas (mm/Tahun) & 2359 & 3087 & 3552 & 3985 & 4020 \\
\hline Intensitas (mm/Jam) & 0.38 & 0.49 & 0.57 & 0.63 & 0.64 \\
\hline
\end{tabular}


Tabel 2. Tutupan lahan dan kemiringan

\begin{tabular}{lccccc}
\hline \multirow{2}{*}{ Tutupan Lahan/Kemiringan } & \multicolumn{5}{c}{ Luas (Ha) } \\
\cline { 2 - 6 } & $0-8 \%$ & $8-15 \%$ & $15-25 \%$ & $25-40 \%$ & $>40 \%$ \\
\hline Belukar & 550,5 & 56,1 & 21,2 & 29,6 & - \\
\hline Hutan Mangrove Sekunder & 42,6 & - & - & - & - \\
\hline Hutan Primer & 14,7 & 22,4 & 211,5 & 301,6 & - \\
\hline Hutan Sekunder & 9,8 & 73,1 & 50,9 & 67,0 & - \\
\hline Pemukiman & 123,3 & - & - & - & - \\
\hline Perkebunan & 472,3 & 14,0 & 17,7 & 12,0 & - \\
\hline Pertanian Lahan Kering & 101,5 & - & - & - & - \\
Campur Semak & & & &
\end{tabular}

Tabel 3. Debit limpasan saat periode ulang

\begin{tabular}{lrrrrrr}
\hline \multicolumn{1}{c}{ Tutupan Lahan } & $\begin{array}{c}\text { Luas } \\
\text { (ha) }\end{array}$ & \multicolumn{5}{c}{$\begin{array}{c}\text { Debit limpasan saat periode ulang } \\
\left(\mathrm{m}^{3} / \text { jam }\right)\end{array}$} \\
\cline { 3 - 7 } & & \multicolumn{1}{c}{2} & 5 & 10 & 25 & \multicolumn{1}{c}{50} \\
\hline Belukar & 657.4 & 464 & 598 & 696 & 769 & 794 \\
\hline Hutan Mangrove Sekunder & 42.6 & 13 & 17 & 19 & 21 & 22 \\
\hline Hutan Primer & 550.2 & 289 & 373 & 434 & 480 & 495 \\
\hline Hutan Sekunder & 200.8 & 105 & 135 & 157 & 173 & 179 \\
\hline Pemukiman & 123.3 & 351 & 453 & 527 & 583 & 601 \\
\hline Perkebunan & 516 & 288 & 371 & 432 & 477 & 492 \\
\hline Pertanian Lahan Kering Campur Semak & 101.5 & 54 & 70 & 81 & 90 & 92 \\
\hline Total & 2191.8 & 1.564 & 2.017 & 2.346 & 2.593 & 2.676 \\
\hline
\end{tabular}

\section{c) Peningkatan Debit Limpasan Permukaan Akibat Perubahan Tutupan Lahan}

Kegiatan penyiapan lahan berupa land clearing akan meningkatan nilai koefisien run-off (C), sedangkan pengurugan dan pemadatan akan mengurangi laju infiltrasi air hujan. Pengurangan laju infiltrasi akan semakin masif ketika diatas tanah tersebut sudah tertutup bangunan/beton. Lahan yang digunakan memiliki luasan mencapai 161 Ha. Debit aliran permukaan ini jika tidak dikelola dengan baik tentunya akan menyebabkan genangan-genangan atau bahkan banjir, dan dapat mengganggu masyarakat disekitar lokasi kegiatan.

Berdasarkan observasi lapangan, lokasi kegiatan tertutup lapisan aluvial, dengan kandungan liat tinggi dan setelah penjenuhan awal, infiltrasi menurun, sehingga dapat dimasukan kedalam kelompok hidrologi B (Potensi run-off sedang, seperti tanah dangkal, kandungan liat tinggi dan setelah penjenuhan awal, infiltrasi menurun). Topografi lokasi kegiatan tersebut memiliki kemiringan antara $0-2 \%$. Penutup lahan di lokasi kegiatan didominasi oleh hutan sehingga koefisien run-off untuk daerah tersebut adalah 0.08. Dengan rata-rata curah hujan 
tahunan sebesar $2.710 \mathrm{~mm}$ dan rata-rata hari hujan dalam satu bulan adalah 16 hari, maka diperkirakan debit limpasan permukaan di lokasi tersebut sebelum ada pembangunan diperkirakan sebesar $\pm 1.185 \mathrm{~m}^{3} /$ hari hujan saat curah hujan normal dan dapat mencapai $>19,320 \mathrm{~m}^{3} /$ hari hujan jika terjadi cuaca ekstrim. Perubahan Debit Aliran Permukaan (run-off) akibat perubahan tutupan lahan dapat dilihat pada Tabel 4. Berdasarkan tabel tersebut, diperkirakan akan terjadi peningkatan debit limpasan permukaan yang mencapai $3,332 \mathrm{~m}^{3} /$ Hari hujan atau $139 \mathrm{~m}^{3} / \mathrm{jam}$. Saat curah hujan esktrim diperkirakan akan terjadi peningkatan aliran permukaan yang mencapai $54,324 \mathrm{~m}^{3} /$ hari.

a) Banjir

Adanya peningkatan aliran permukaan akibat pembukaan lahan yang diperkirakan mencapai $\pm 3,332 \mathrm{~m} 3 /$ hari hujan saat curah hujan normal dan bahkan diperkirakan mencapai > 54,324 $\mathrm{m} 3 /$ hari hujan saat terjadi hujan ekstrim, dapat menyebabkan terjadinya banjir atau genangan di sekitar lokasi rencana kegiatan. Banjir di defenisikan sebagai tergenangnya suatu tempat akibat meluapnya air yang melebihi kapasitas pembuangan air disuatu wilayah dan menimbulkan kerugian fisik, sosial dan ekonomi (Rahayu dkk, 2009). Jika dilihat dari pola alirannya, limpasan permukaan (runoff) akan menuju kearah tenggara dari lokasi kegiatan. Aliran tersebut akan mengikuti badan air yang menuju kampung Warsuy kemudian menuju samudera pasifik. Badan air atau sungai kecil ini berada di DAS Ransiki, akan tetapi aliran sungainya tidak bergabung dengan Sungai Ransiki, tetapi langsung menuju pantai timur Ransiki (Samudra Pasifik) (Gambar 4).

Dari pengamatan dilapangan, kondisi hidrologi badan air yang akan dilewati oleh aliran limpasan permukaan memiliki lebar $<5 \mathrm{~m}$ dan kedalam bervariasi antara $1-2 \mathrm{~m}$. Badan air memiliki dasar tanah, berkelok, berumput tidak terawat sehingga memiliki koefisien manning $0.023-0.050$. Kemiringan (slope) badan air bervariasi, antara $1.1 \%$ sampai dengan $5.7 \%$ dan gradien hidrolisnya 0.08 . Diperkirakan badan air ini memiliki kapasitas tampung sekitar $9.500-24.600 \mathrm{~m} 3 /$ jam.

Jika dibandingkan dengan debit limpasan yang berasal dari SubDAS Ransiki sebesar $2.676 \mathrm{~m} 3 /$ jam dan ditambah debit limpasan yang berasal dari kompleks perkantoran sebesar $139 \mathrm{~m} 3 / \mathrm{jam}$, kapasitas tampung saluran ini masih lebih besar, namun demikian yang perlu diperhatikan adalah lebar dan kedalaman (luas penampang) saluran air yang tidak sama di semua titik. Ada bebarapa titik yang memiliki luas penampang kecil, sehingga diperkirakan tidak bisa menampung limpasan permukaan saat hujan ekstrim.

Tabel 4. Peningkatan debit limpasan permukaan

\begin{tabular}{lrrrrrr}
\hline Peruntukan & $\begin{array}{c}\text { Luas } \\
\left(\mathrm{m}^{2}\right)\end{array}$ & $\begin{array}{c}\text { Intensitas } \\
\text { hujan } \\
\text { Rata-rata } \\
(\mathrm{mm} / \text { hari })\end{array}$ & $\begin{array}{c}\text { Intensitas } \\
\text { ekstrim } \\
(\mathrm{mm} / \mathrm{hari} \\
\text { hujan })\end{array}$ & $\begin{array}{c}\text { Koefisie } \\
\mathrm{n} \text { runoff } \\
\text { saat ini }\end{array}$ & $\begin{array}{c}\text { Debit } \\
\left(\mathrm{m}^{3} / \text { Hari }\right. \\
\text { hujan })\end{array}$ & $\begin{array}{c}\text { Debit } \\
\text { Ekstrim } \\
\left(\mathrm{m}^{3} / \text { Hari }\right. \\
\text { hujan })\end{array}$ \\
\hline Bangunan & 2.4505 & 9.2 & 150 & 0.9 & 203 & 3,308 \\
\hline $\begin{array}{l}\text { Jalan dan } \\
\text { Lapangan }\end{array}$ & 10.6 & 9.2 & 150 & 0.75 & 731 & 11,925 \\
\hline Taman & 0.5 & 9.2 & 150 & 0.25 & 12 & 188 \\
\hline Area Hijau & 118.478 & 9.2 & 150 & 0.17 & 1,853 & 30,212 \\
\hline Halaman Kantor & 28.9705 & 9.2 & 150 & 0.2 & 533 & 8,691 \\
\hline & & & & Total & 3,332 & 54,324 \\
\hline
\end{tabular}




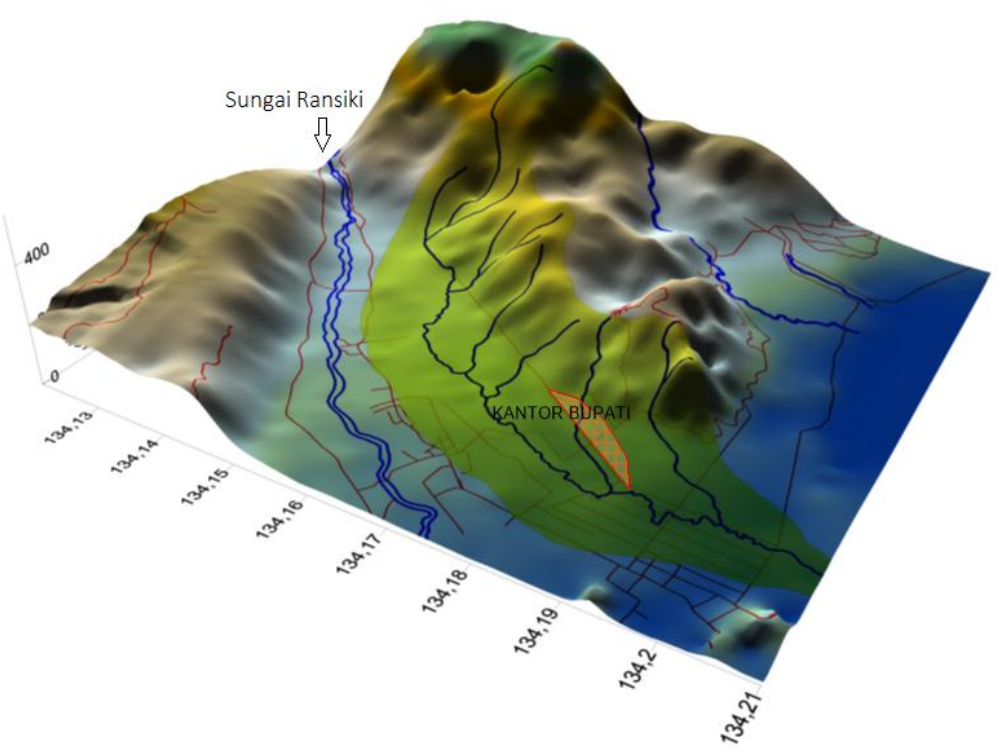

Gambar 4. Penampang 3D SubDAS di lokasi kegiatan

\section{KESIMPULAN}

1) Debit puncak limpasan permukaan di SubDAS Ransiki untuk periode ulang 2 tahun mencapai 1.564 $\mathrm{m}^{3} / \mathrm{jam}$, periode ulang 5 tahun mencapai $2.017 \mathrm{~m}^{3} / \mathrm{jam}$, periode ulang 10 tahun mencapai 2.346 $\mathrm{m}^{3} / \mathrm{jam}$, periode ulang 20 tahun mencapai $2.593 \mathrm{~m}^{3} / \mathrm{jam}$, dan periode ulang 50 tahun mencapai 2.676 $\mathrm{m}^{3} / \mathrm{jam}$.

2) Debit Aliran Permukaan (run-off) akibat perubahan tutupan lahan di kompleks perkantoran Bupati Manokwari Selatan diperkirakan mencapai 3,332 $\mathrm{m}^{3} /$ Hari hujan atau $139 \mathrm{~m}^{3} / \mathrm{jam}$.

3) Debit limpasan yang berasal dari SubDAS Ransiki sebesar 2.676 $\mathrm{m}^{3} / \mathrm{jam}$, ditambah debit limpasan yang berasal dari kompleks perkantoran sebesar $139 \mathrm{~m}^{3} / \mathrm{jam}$, diperkirakan masih dapat ditampung oleh aliran sungai atau badan air terdekat.

\section{DAFTAR PUSTAKA}

Arsyad, S. 1989. Konservasi Tanah dan Air. Bogor: IPB Press.

Asdak, C. 2010. Hidrologi Dan Pengelolaan Daerah Aliran Sungai: Edisi Revisi Kelima. Yogyakarta: Gadjah Mada University Press.

BSN. 2004. Standar Nasional Indonesia 032415-1991: Tata Cara Perhitungan Debit Banjir, Badan Standarisasi Nasional

BSN. 2010. Standar Nasional Indonesia No. 7642 tahun 2010 tentang Klasifikasi Penutup Lahan, Badan Standarisasi Nasional

Holland P.G. (1998) Manning formula. In: Hydrology and Lakes. Encyclopedia of Earth Science. Springer, Dordrecht. https://doi.org/10.1007/1-40204513-1_149

Kirpich ZP. 1940. Time of concentration of small agricultural watersheds. J Civ Eng 10(6):362 
Peraturan Pemerintah Republik Indonesia Nomor 37 Tahun 2012 Tentang Pengelolaan Daerah Aliran Sungai.

Rahayu. Dkk. 2009. Banjir dan Upaya Penanggulangannya. Bandung : Pusat Mitigasi Bencana (PMB-ITB)

Sidral, A., Zende, A.M. 2016. Quantitative Evaluation of Morphometric of Sakli River Using Geospatial Techniques. National Conference on Water Resource \& Flood Management with Special
Reference to Flood Modelling, SVNIT Surat.

Singh V.P. (1998) Log-Pearson Type III Distribution. In: Entropy-Based Parameter Estimation in Hydrology. Water Science and Technology Library, vol 30. Springer, Dordrecht.

Subarkah, I. 1980. Hidrologi untuk Perencanaan Bangunan Air. Bandung : Idea Dharma. 